\title{
Carbon foam prepared by pyrolysis of olive stones under steam
}

\author{
R.V.R.A. Rios, M. Martínez-Escandell, M. Molina-Sabio *, F. Rodríguez-Reinoso \\ Laboratorio de Materiales Avanzados, Departamento de Química Inorgánica, Universidad de Alicante, E-03080 Alicante, Spain
}

Received 30 September 2005; accepted 30 November 2005

The experimental conditions for the pyrolysis of olive stones to produce a swelling of the particle and eventually the formation of carbon foam are described and discussed. The greatest expansion of the material occurred when $200-300 \mathrm{~g}$ of precursor, in the presence of steam at a pressure of $1 \mathrm{MPa}$, is introduced into a $1000 \mathrm{ml}$ stainless steel reactor placed inside a sand-bath furnace previously heated to $500{ }^{\circ} \mathrm{C}$. In a few minutes the pyrolysis begins and this exothermic process leads to a more rapid pyrolysis. A relationship between heating ate and degree of foaming for the resulting char is observed. The carbon foam obtained exhibits a low density, $0.2-0.3 \mathrm{~g} / \mathrm{cm}^{3}$, due to the presence of meso and macropores, mainly those of size larger than $1 \mu \mathrm{m}$. A mechanism is suggested to explain the formation of the foam the formation of the foam.

(c) 2005 Published by Elsevier Ltd.

Keywords: Char; Pyrolysis; Porosity

\section{Introduction}

Biomass pyrolysis is a thermal process usually employed in the preparation of fuels, chemicals and charcoal. It also constitutes the first step in the preparation of thermically (or physically) activated carbon. Briefly, the precursor, with an approximate composition of $50 \mathrm{wt} \% \mathrm{C}, 6 \mathrm{wt} \% \mathrm{H}$ and $44 \mathrm{wt} \% \mathrm{O}$, decomposes upon increasing temperature, releasing $\mathrm{H}_{2} \mathrm{O}, \mathrm{CO}_{2}, \mathrm{CO}$ and a great variety of hydrogen and carbon rich compounds, so that the remaining solid is enriched in aromatic carbon while adopting a structure typical of non-graphitizable carbons [1]. The char yield of the process is near $25 \mathrm{wt} \%$, although this value depends on the selected operation conditions. In general, low heating rates and high pressure facilitate secondary reactions and the conversion to char, while fast pyrolysis using high inert gas flow increases the amount of organic volatiles.

\footnotetext{
* Corresponding author. Tel.: +34 96590 9758; fax: +34 965903454. E-mail address: m.molina@ua.es (M. Molina-Sabio).
}

Studies on pyrolysis of cellulosic and lignocellulosic 36 materials indicate that the largest transformations take 37 place in the $200-400{ }^{\circ} \mathrm{C}$ temperature range, these being 38 accompanied by a fast evolution of gases and an enhance- 39 ment of the solid's temperature. As the particles of precur- 40 sor shrink it is assumed that the decomposition products of 41 the constituting polymers (mainly cellulose, hemicellulose 42 and lignin) react to form a series of linked chemical bonds 43 and the solid, which becomes richer in carbon, progres- 44 sively gets rigid. The evolved gases leave the solid through 45 the channels present in the structure of the vegetal, thus 46 enabling the shrinkage of particles and the maintenance 47 of the precursor appearance [2]. Consequently, the forma- 48 tion of carbon foam by pyrolysis of these precursors is 49 not common and it has not being previously reported. $\quad 50$

Since the first development of carbon foam from ther- 51 mosetting organic polymers, advances in finding new pre- 52 cursors and the preparation of carbon foam from coal 53 [3], mesophase pitch [4,5], polyimide [6], etc., have been 54 described. The use of lignocellulosic precursors, due to its 55 low cost, can constitute an interesting alternative. $\quad 56$ 


\section{2. Experimental}

\section{2} [8]. lished [9].
Although there are no publications related to the preparation of carbon foam from cellulosic and lignocellulosic materials, some authors [7] have reported that during the flash pyrolysis of almond shells pretreated at $300{ }^{\circ} \mathrm{C}$, a dilatation of $20 \%$ occurred instead of the expected shrinkage. In a similar way, the expansion of the particles after the flash pyrolysis of milled cedar sawdust has been described

This work analyses the pyrolysis conditions required for the expansion of a granular lignocellulosic material such as olive stones, in order to obtain carbon foam. The process involves the transformation of the precursor grains into a block of continuous material in which the grain boundaries cannot be distinguished.

\subsection{Thermal treatment}

The precursor, olive stones, ground to a uniform particle size $(3.5 \mathrm{~mm})$, is loaded in a glass tube $(65 \mathrm{~mm}$ internal diameter) which is introduced into a $1000 \mathrm{ml}$ stainless steel reactor placed inside a sand-bath furnace previously heated to $500{ }^{\circ} \mathrm{C}$. A thermocouple inserted in the centre of the bed of the precursor registers the solid temperature during pyrolysis, and another thermocouple placed near the outlet of the reactor $(5 \mathrm{~cm}$ below) detects the temperature of the gases evolved during pyrolysis. The system can operate at pressures as high as $1.5 \mathrm{MPa}$, and controlled depressurisation is possible. The heat transfer to the reactor is carried out using a fluidised sand bed furnace which is previously heated to $500{ }^{\circ} \mathrm{C}$. A scheme of the system was already pub-

Table 1 presents the conditions selected for pyrolysis. As an example, experiment 1 has been carried out as follows: the glass tube charged with $200 \mathrm{~g}$ of the precursor is introduced at room temperature into the reactor which already contains $25 \mathrm{ml}$ of water. Next, the reactor is filled with nitrogen at $1 \mathrm{MPa}$ and introduced in the sand-bath furnace where it is externally heated. Pressure is kept constant inside the reactor during the experiment, as the gas outlet has a pressure control valve. When the temperature of the solid reaches $500{ }^{\circ} \mathrm{C}$, the furnace is removed and the reactor is depressurised.

In the majority of the experiments (see column 2 in Table 1), $25 \mathrm{ml}$ of water were incorporated into the reactor, around the glass tube, in order to generate a steam-rich atmosphere before the beginning of the pyrolysis. In experiments 10 and 11 sodium chloride was dissolved in the $25 \mathrm{ml}$ of water. In addition to the environment in which the reaction takes place (experiments 1-5), other conditions such as pressure (experiments $1,6,7$ ) or the amount of precursor (experiments $1,8,9$ ) have been modified. In the experiments 12 and 13 the furnace has also been heated to $500{ }^{\circ} \mathrm{C}$ but the pyrolysis was interrupted at $150{ }^{\circ} \mathrm{C}$ and $220^{\circ} \mathrm{C}$, respectively.

\subsection{Dimension change and porosity}

The thermal treatment introduces visible changes in the product obtained, either because the precursor grains swell, or because the grains aggregate to form foam. In the majority of the experiments the final block of material is constituted by areas with the aspect of foam and other more external areas which are granular, both types of area being easy to separate. The degree of foaming is defined as the weight percentage of the char obtained as foam (Table $1)$.

The bulk density of the foam has been determined by weighting a block of known dimensions. The volume of large meso and macropores has been quantified by mercury porosimetry (Carlo Erba 200), and the surface and cavities produced during pyrolysis have been examined by SEM (Jeol JSM-840). For the chars obtained mainly in granular form $(5,6,7$ and 11), the average particle diameter has been determined using a photographic system, and counting and sizing a representative amount of particles. The bulk density of granular chars has also been determined

Table 1

Pyrolysis conditions

\begin{tabular}{|c|c|c|c|c|c|}
\hline Experiment & Initial atmosphere & Amount of precursor $(\mathrm{g})$ & Pressure (MPa) & Temperature $\left({ }^{\circ} \mathrm{C}\right)$ & Degree of foaming $(\%)$ \\
\hline 1 & $\mathrm{~N}_{2}+\mathrm{H}_{2} \mathrm{O}$ & 200 & 1.0 & 500 & 73 \\
\hline 2 & $\mathrm{CO}_{2}+\mathrm{H}_{2} \mathrm{O}$ & 200 & 1.0 & 500 & 80 \\
\hline 3 & Air $+\mathrm{H}_{2} \mathrm{O}$ & 200 & 1.0 & 500 & 69 \\
\hline 4 & $\mathrm{O}_{2}+\mathrm{H}_{2} \mathrm{O}$ & 200 & 1.0 & 500 & 27 \\
\hline 5 & $\mathrm{~N}_{2}$ & 200 & 1.0 & 500 & 0 \\
\hline 6 & $\mathrm{~N}_{2}+\mathrm{H}_{2} \mathrm{O}$ & 200 & 0.1 & 500 & 0 \\
\hline 7 & $\mathrm{~N}_{2}+\mathrm{H}_{2} \mathrm{O}$ & 200 & 0.5 & 500 & 5 \\
\hline 8 & $\mathrm{~N}_{2}+\mathrm{H}_{2} \mathrm{O}$ & 50 & 1.0 & 500 & 59 \\
\hline 9 & $\mathrm{~N}_{2}+\mathrm{H}_{2} \mathrm{O}$ & 300 & 1.0 & 500 & 82 \\
\hline 10 & $\mathrm{~N}_{2}+\mathrm{NaCl}(\mathrm{aq})^{\mathrm{a}}$ & 200 & 1.0 & 500 & 84 \\
\hline 11 & $\mathrm{~N}_{2}+\mathrm{NaCl}(\mathrm{aq})^{\mathrm{b}}$ & 200 & 1.0 & 500 & 0 \\
\hline 12 & $\mathrm{~N}_{2}+\mathrm{H}_{2} \mathrm{O}$ & 200 & 1.0 & 150 & 32 \\
\hline 13 & $\mathrm{~N}_{2}+\mathrm{H}_{2} \mathrm{O}$ & 200 & 1.0 & 220 & 47 \\
\hline
\end{tabular}

\footnotetext{
${ }^{a} \mathrm{NaCl}$ aqueous solution, $5 \mathrm{wt} \%$.
}

b $\mathrm{NaCl}$ aqueous solution, $20 \mathrm{wt} \%$. 
130 by weighting a calibrated volume filled with the char 131 (method ASTM D 2854-89).

\section{2.3. Structure and chemical nature}

133 The chemical nature and composition of the chars 1 and 1345 have been determined by the following techniques: ele135 mental analysis (Carlo Erba CHNSO EA1108), FTIR spec136 troscopy (Matson Infinity Gold spectrometer) and XPS, 137 model VG-Microtech Multilab 3000. As the chars at $138500{ }^{\circ} \mathrm{C}$ are semi-carbonized, the results obtained are rather 139 erratic. In order to obtain representative values a large 140 amount of the char has been milled to a particle size below $141100 \mu \mathrm{m}$ and the analyses have been carried out using four 142 different portions of the sample and the results averaged.

\section{3. Results and discussion}

\section{3.1. Experimental conditions that lead to the formation 145 of carbon foam}

Fig. 1 plots the variation of the temperature for both the furnace, solid and gas outlet during the pyrolysis for experiments 1 and 5 of Table 1 . The initial temperature of the furnace, $500{ }^{\circ} \mathrm{C}$, slightly decreases when it gets in contact with the reactor, which is originally at room temperature. Since the reactor mass is rather large in respect to that of precursor, the temperature profile of the furnace for all experiments is very similar.

In experiment 5, the profile shows that the solid's temperature increases faster as from $10 \mathrm{~min}$, with a pseudostep at around $150-200^{\circ} \mathrm{C}$ and reaching $23^{\circ} \mathrm{C} / \mathrm{min}$ for the temperature range $200-400^{\circ} \mathrm{C}$. Gas temperature also increases as from $10 \mathrm{~min}$, but the profile shows a maximum at around $200^{\circ} \mathrm{C}$. The most intense transformations of the precursor seem to end at about $400{ }^{\circ} \mathrm{C}$, when the solid's temperature increases more slowly and the gas temperature remains constant.

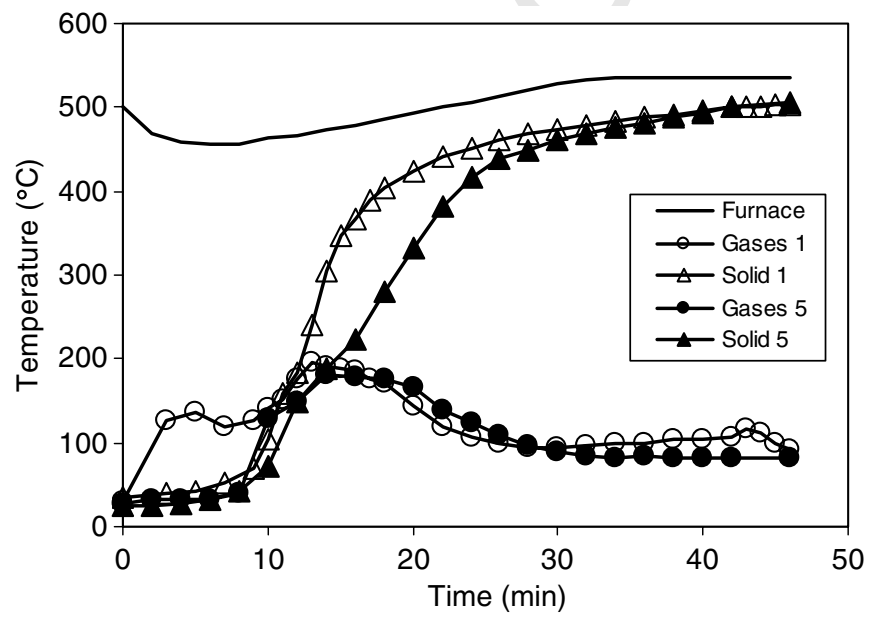

Fig. 1. Evolution of sand-bath furnace temperature, solid temperature and gas outlet temperature during pyrolysis.
Experiment 1 uses the same conditions as 5, but with the 163 addition of $25 \mathrm{ml}$ of water to the reactor. This seems to affect the solid temperature profile in two ways: (a) the pseudo-step (change in heating rate) at $150{ }^{\circ} \mathrm{C}$, is shorter in experiment 1; and (b) the heating rate in the temperature range $200-400^{\circ} \mathrm{C}$ is $45^{\circ} \mathrm{C} / \mathrm{min}$ for the experiment 1 , almost double than for experiment 5 . The gas temperature profile in both experiments is similar, the only difference being the small maximum found at $5 \mathrm{~min}$ from the start of experiment 1 , due to the boiling of the water.

The char yield after experiment 5 was $35 \mathrm{wt} \%$, slightly higher than $33 \mathrm{wt} \%$ from experiment 1 . Nevertheless, the more marked differences are in the physical shape of the product. Whereas all the char of experiment 5 is in granular shape, $27 \mathrm{wt} \%$ of solid 1 is granular and the rest, $73 \mathrm{wt} \%$, constitutes a whole block. The granular part of the sample is located near the internal lateral walls of the glass tube inside the reactor, whereas the block occupies the centre and bottom of the tube. When the block is fractured, no interparticulate spaces are observed and the porous structure seems to be completely different to the cellular structure of the precursor.

Fig. 2 includes the temperature profiles of experiments $1 \mathrm{R}$ and $5 \mathrm{R}$, carried out in a similar way as experiments 1 and 5 , but without precursor. The similarity between the two later profiles, in agreement with the small differences in thermal conductivity for nitrogen and steam [10], indicates that the heat transfer rate from the furnace to the precursor is the same in experiments 1 and 5. Therefore, the observed differences in the solid's temperature profiles plotted in Fig. 1 are due to differences in the heat generated during pyrolysis.

The shape of the temperature profiles for the solid in most experiments is similar to that described in Fig. 1 for solids 1 and 5. However, some samples exhibit a different profile, as shown in Fig. 2 for experiments 4, 8 and 11. For instance, the high concentration $(20 \mathrm{wt} \%)$ of $\mathrm{NaCl}$ in experiment 11 enhances the boiling temperature of the

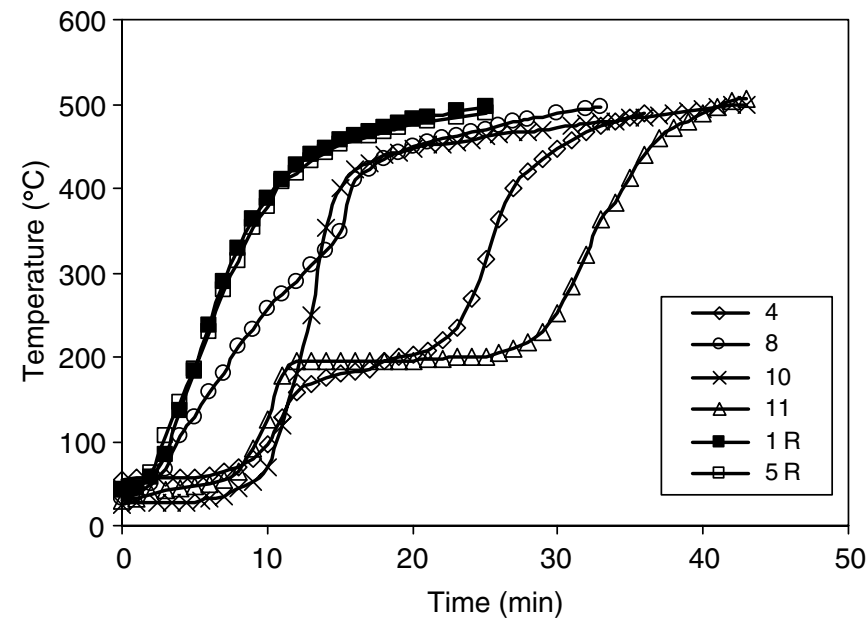

Fig. 2. Influence of pyrolysis conditions on the temperature profiles for the solids. 
solution but also the heat demand to carry out the phase change. As a result, the temperature remains almost constant for some minutes and the heating rate for the solid in the $200-400{ }^{\circ} \mathrm{C}$ range is lower than for experiment 10 , for which the $\mathrm{NaCl}$ concentration is $5 \mathrm{wt} \%$. In experiment 4, oxygen stabilises intermediate products of pyrolysis, which require extra heat for their decomposition. Finally, the profile of experiment 8 is intermediate of the profiles of experiments 1 (Fig. 1) and $1 \mathrm{R}$ as the method to measure temperature is very sensitive to the amount of precursor introduced, which was smaller in run 8 . The shape of this curve constitutes a proof of the difficulties in measuring experimentally the real temperature of the solid. Therefore, all the profiles shown in Figs. 1 and 2 must be considered as an approximation to the real temperature of the solid.

Fig. 3 presents the degree of foaming as a function of the heating rate of the solid deduced from the linear portion of the temperature profile in the temperature range 200$400{ }^{\circ} \mathrm{C}$. The relation found indicates that a minimum heating rate of $30^{\circ} \mathrm{C} / \mathrm{min}$ is necessary to initiate the formation of the foam, which is extensive for heating rates higher than $50^{\circ} \mathrm{C} / \mathrm{min}$. Thus, during experiment 10 , similar to experiment 1 but incorporating $5 \mathrm{~g} \mathrm{NaCl}$ to the $25 \mathrm{ml}$ of water, a heating rate of $74{ }^{\circ} \mathrm{C} / \mathrm{min}$ is reached after the initial $10 \mathrm{~min}$ (Fig. 2), with an $84 \mathrm{wt} \%$ of foam being formed.

When the heating rate is below $30^{\circ} \mathrm{C} / \mathrm{min}$ the chars are essentially granular, although the particle size is larger than that obtained in a conventional pyrolysis. Thus, the average particle diameter of the precursor, $3.5 \mathrm{~mm}$, is reduced to $2.6 \mathrm{~mm}$ in a traditional pyrolysis at $500{ }^{\circ} \mathrm{C}$, whereas for the chars obtained in experiments 5, 6, 7 and 11, a larger particle size is obtained, $3.0,2.8,3.2$, and $2.8 \mathrm{~nm}$, respectively. Therefore, it can be concluded that the swelling of the particle is an intermediate step for the formation of the foam.

The values for the degree of foaming in Table 1 indicate that, with the experimental system used here, the formation of the carbon foam during pyrolysis is favoured when

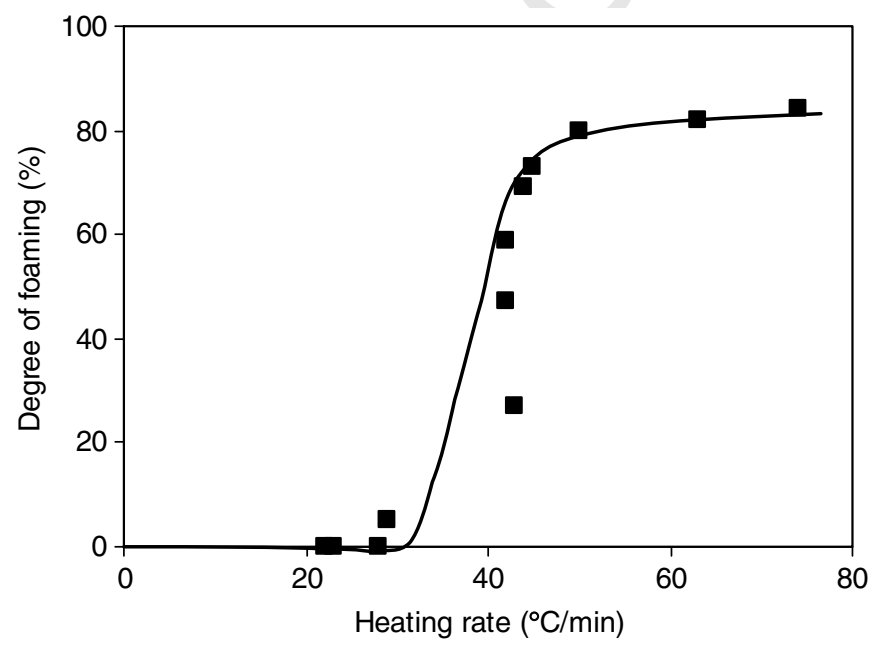

Fig. 3. Relation between degree of foaming and heating rate of the solid. steam is generated in the presence of inert gas (experiments 239 $1-5$ ), under a pressure of $1.0 \mathrm{MPa}$ (experiments $1,6,7$ ), and 240 filling with the precursor at least $2 / 3$ of the reactor's volume (experiments $1,8,9$ ). Besides, if the boiling point of water is increased by the addition of $\mathrm{NaCl}$ (experiments $1,10,11)$, the degree of foaming increases, but it is inhibited if the concentration of salt in the solution is high. Finally, it must be pointed out that the expansion occurs from the beginning of pyrolysis (experiments $1,12,13$ ).

No relation between the char yield and the degree of foaming has been found. Just to comment that the char yield of experiment 5 was $35 \mathrm{wt} \%$, while in the rest of the experiments, where steam was generated before pyrolysis, the char yield is $32-33 \mathrm{wt} \%$. This indicates that steam facilitates the extraction of volatiles, possibly the more soluble ones [11], due to the increase in the extraction strength of water at $1 \mathrm{MPa}$ and temperatures above $200{ }^{\circ} \mathrm{C}$ and also to the increase in the flow of gas at the outlet of the reactor produced by the addition of $25 \mathrm{ml}$ of water. In any case, the char yield obtained with this faster pyrolysis is lower than that obtained at the same temperature using a controlled heating rate of $1{ }^{\circ} \mathrm{C} / \mathrm{min}$ at $1.0 \mathrm{MPa}, 41-42 \mathrm{wt} \%$ [12], and similar to that obtained in a conventional ambient pressure pyrolysis at $500{ }^{\circ} \mathrm{C}(31 \mathrm{wt} \%)$.

\subsection{Density and appearance}

The char obtained in experiment 1 was constituted by $73 \mathrm{wt} \%$ foam and $27 \mathrm{wt} \%$ granular char and Fig. 4 shows the SEM images of foam $(\mathrm{a}-\mathrm{c})$ or granular (d) sections. A transversal cut of the foam block (a) shows that a continuous mass with a different appearance to the precursor is forming, where no grain boundaries can be detected. A higher magnification image (b) shows the existence of voids/pores with size in the range of several tens of microns and even up to $100 \mu \mathrm{m}$. Observing the surface with more detail (c), a smooth texture is visible, in contrast to that of a char prepared in a conventional pyrolysis, which is rough and reflects the cellular structure of the precursor $[13,14]$. A group of fissures and blisters can be observed in the surface of the granular fraction (d), the aspect of which suggests that they have been generated by the release of gases throughout a liquid of high viscosity. In the same way, a labyrinth of holes has formed in the fractured grain, some of them exhibiting an unusual large size. The images of the rest of the chars are similar to those of Fig. 4, taking into account that the lower the degree of foaming the lower is the size of the voids.

The bulk density of the fraction of carbon obtained as foam ranges from 0.32 to $0.22 \mathrm{~g} / \mathrm{cm}^{3}$, values that can be considered low since there is not any free space between the particles, whereas the bulk density for the granules is higher $\left(0.48-0.31 \mathrm{~g} / \mathrm{cm}^{3}\right)$. In both cases, a linear decrease of bulk density with the degree of foaming is observed, the decrease being more pronounced for the granular fraction. This means that increasing degree of foaming leads to 


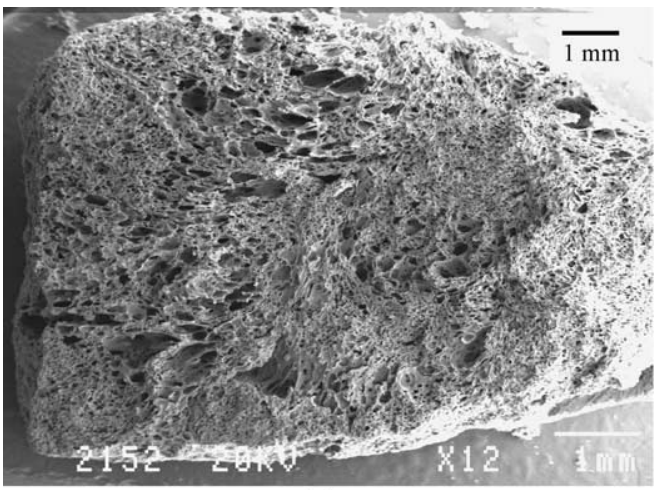

(a)

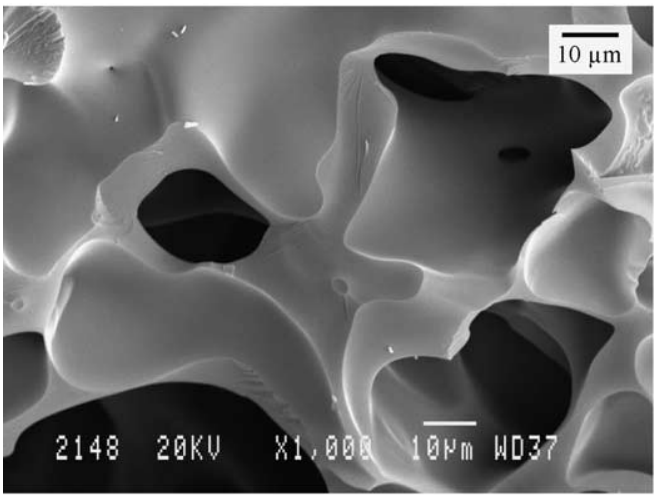

(c)

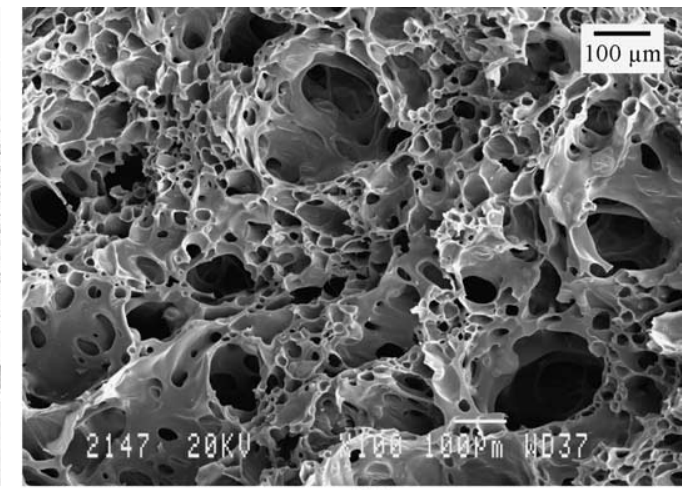

(b)

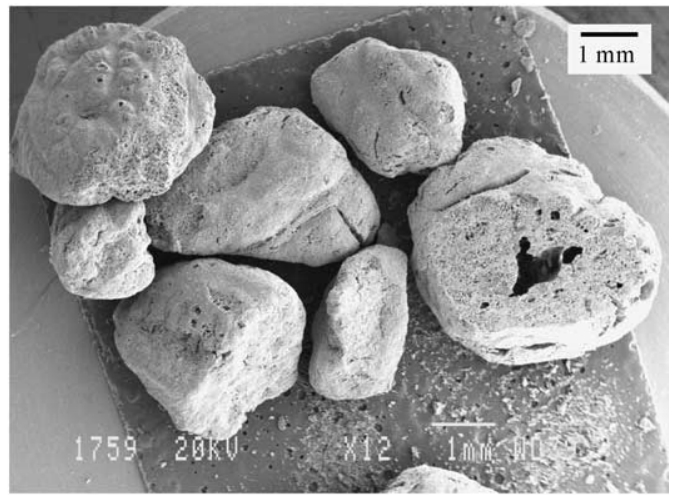

(d)

Fig. 4. SEM images of a section of char 1 in foam shape $(a-c)$ and in granular

293 a logical lower amount of char in granular form, the gran294 ules being more swollen and, consequently, more porous.

295 The micropore volume of these chars, estimated from 296 the adsorption isotherms of $\mathrm{N}_{2}$ at $77 \mathrm{~K}$ and $\mathrm{CO}_{2}$ at $297273 \mathrm{~K}$, is rather low, approximately $0.02 \mathrm{~cm}^{3} / \mathrm{g}$. Conse298 quently, the low density of the carbon foam may be caused 299 by the presence of macro and mesopores, which have been 300 evaluated by mercury porosimetry; this technique yields 301 curves for cumulative pore volume (see Fig. 5) in the size 302 range $15 \mu \mathrm{m}$ to $7 \mathrm{~nm}$ (pressure range, 0.1-20 $\mathrm{MPa}$ ). Since 303 the foams have voids larger than $15 \mu \mathrm{m}$ (and even up to $304100 \mu \mathrm{m}$, see Fig. 4) the pore volume in the $100-15 \mu \mathrm{m}$ has 305 also been determined; for this measurement the picnometer 306 containing the sample was filled with mercury under vac307 uum and the drop in the calibrated capillary was measured 308 when the picnometer is exposed to atmospheric pressure. 309 This value has been added to those obtained in the poros310 imetry curves, to build up Fig. 5.

311 In general terms, the pore volume for carbon foams is 312 much higher than for the granular char 5, exceeding in 313 some cases the value of $4 \mathrm{~cm}^{3} / \mathrm{g}$; most (60-80\%) of the pore 314 volume corresponds to macropores with a size larger than $3151 \mu \mathrm{m}$, visible under an optical microscope. The comparison 316 of the curves 1-4 shows the evolution of porosity along 317 foaming. Thus, the transition from low to medium degree 318 of foaming (curves 4 and 3) produces a preferential devel319 opment of the pores in a size range of 30-300 nm, whereas 320 for the largest foaming (curves 1 and 2), the differences are

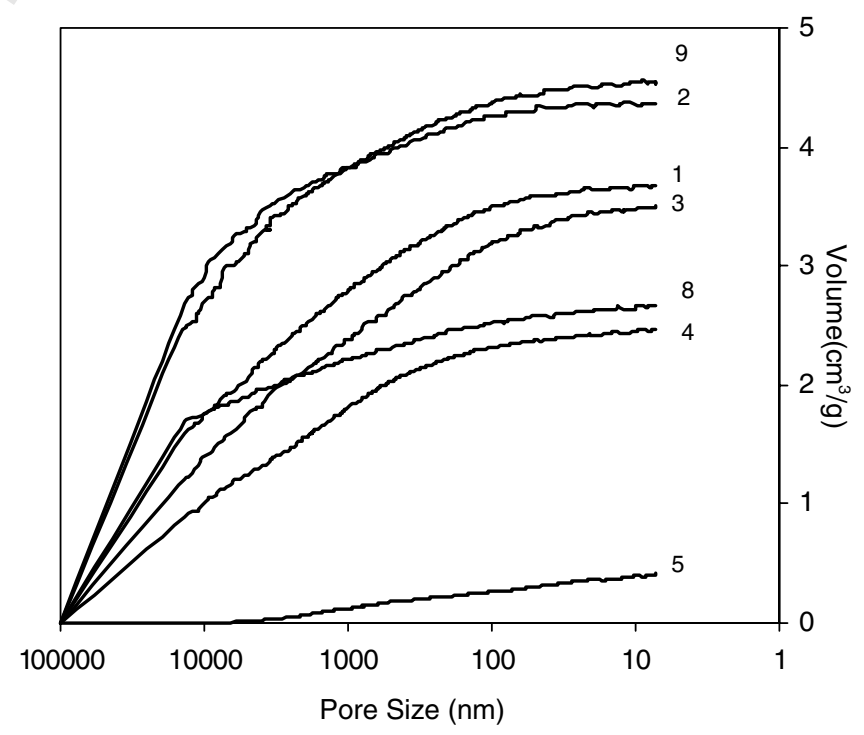

Fig. 5. Volume distribution of meso and macropores (mercury porosimetry) for several carbon foams and granular chars.

observed in the larger pore size, indicating that pores of increasing size are produced during the expansion. This effect is more noticeable when comparing the curves for foams 8, 1 and 9 (degree of foaming of 59\%,73\% and $82 \%$, respectively), where the formation of pores smaller than $10 \mu \mathrm{m}$ is followed by formation of pores of larger dimensions. 


\subsection{An interpretation of the foam formation}

The above results indicate that the pyrolysis of a large amount of precursor at high pressure and in the presence of steam occurs fast and leads to the formation of a carbon foam.

Olive stones have three major constituents: the natural polymers lignin $(39 \%)$, hemicellulose $(25 \%)$ and cellulose $(36 \%)$. Its structure can be referred as a composite where the cellulosic fibres are held together in a lignin and hemicellulose matrix. In order to expand the precursor, the experimental conditions must facilitate: (i) the softening of the matrix, especially the lignin, as it is the main responsible for the mechanical resistance of the precursor, (ii) depolymerization of some components into an intermediate product which can be considered a "melt" of high viscosity, and (iii) foaming by the volatile matter evolved from the melt before polymerization into a solid occurs.

Previous work [15] reported that the lignin softens in the presence of steam even at $90{ }^{\circ} \mathrm{C}$ without a significant decomposition and this fact is used in the manufacture of shaped furniture. Consequently, the precursor particles may be soft when pyrolysis begins, thus allowing for the expansion of the precursor as from the first stages of pyrolysis, as it could be observed in experiments 12 and 13 (where pyrolysis was interrupted at 150 and $220^{\circ} \mathrm{C}$, respectively).

On the other hand, if part of the precursor is to be transformed into intermediate "melt" and then into volatiles one has to admit that fragmentation of biopolymers is taking place in addition to dehydration. It is well known that if the heating rate experimented by the solid is high, as in the so-called fast pyrolysis, the depolymerization/fragmentation reactions compete with dehydration reactions, which are almost exclusive during conventional pyrolysis [16-20]. The studies carried out with cellulose indicate that fast pyrolysis produces depolymerization to give the monomer levoglucosan, oligomers and other volatile compounds. It is probable that at high pressure the volatiles remain in the particle as a liquid, which boils or decomposes to gases when the temperature is increased. This will cause a local pressure increase within the particle, allowing first for its expansion and then for the formation of the foam.

Although the pyrolysis carried out in this work cannot be considered fast pyrolysis, the heating rate for the solid is high and the results of Fig. 3 seem to indicate that the larger the heating rate the larger is the transformation from granular to foam. According to Mok and Antal [21], the char produced in the transformation of the products of the depolymerization of cellulose is soft and fluffy, as suggested by Fig. 4c. However, the char from the dehydration has a strong structural integrity and retain the precursor shape, as it is usually observed in the char obtained in a conventional pyrolysis of the same precursor.

The experiment 1 of Fig. 1 can be interpreted according to the model of biomass decomposition [20]: the heat supplied to the reactor is first employed to evaporate the $25 \mathrm{ml}$ of water, increasing its partial pressure and, since it retards dehydration, it softens the precursor's matrix. When the precursor reaches a temperature around $150{ }^{\circ} \mathrm{C}$ there is a pseudo-step that can be interpreted as a scission of the biopolymers of the precursor (endothermic process) to produce the high viscosity "melt" which undergoes dehydration, an exothermic process. This exothermic process leads to a faster pyrolysis and facilitates further fragmentations to produce monomers and/or dimers [16]. These volatiles initially remain as liquid because of the pressure inside the reactor, but boiling or decomposition take place when the temperatures increases, thus producing the expansion of the particles. Such expansion is large enough to put into contact neighbouring particles and, if the local temperature is high enough, as in the centre of the reactor, the viscosity of the "melt" will facilitate their coalescence (see Fig. 4c).

The behaviour described above is different from the one found in a conventional pyrolysis because in the latter the dehydration reactions predominate, thus favouring the formation of stable cross-linked bonds. The gases (mainly $\mathrm{H}_{2} \mathrm{O}, \mathrm{CO}_{2}$ and $\mathrm{CO}$ ) are released to the exterior of the particle through the transport channel of the vegetal material and the particle does not swell but it shrinks.

To analyse if the degree of expansion is related to the composition of the chars obtained at $500{ }^{\circ} \mathrm{C}$, Table 2 collects the data corresponding to char $5(0 \%$ foaming) and char 1 ( $73 \%$ foaming).

XPS and elemental analysis results indicate that the foam contains lower oxygen content that the same product in granular shape, the differences being more marked in char 5. In a similar fashion the FTIR spectra of char 1 (granular) and char 5 exhibit a slight enhancement in the signal at $1100-1300 \mathrm{~cm}^{-1}$, indicative of the $\mathrm{C}-\mathrm{O}$ bond. Therefore, it is possible to assume that the "melt" have lower viscosity when the oxygen content is low, thus facilitating the formation of the foam. For the same reason, one can expect a trend relating the formation of the foam to the aromaticity of the chars. However, there is no agreement between the results obtained with the different techniques. Thus, the results from elemental analysis and FTIR spectra seem to indicate that the aromaticity is higher in the foam than in the granular fraction, although the aromaticity quantified by the relative intensity of the band $\mathrm{C}_{1 \mathrm{~s}}$ at $284 \mathrm{eV}$ does not follow the same order. Therefore, some additional experiments are needed to clarify the chemical changes that lead to the formation of a foam.

Table 2

Oxygen content and aromaticity of some chars

\begin{tabular}{|c|c|c|c|c|c|}
\hline \multirow[t]{2}{*}{ Char } & \multirow{2}{*}{$\begin{array}{l}\text { FTIR } \\
\text { C-- } H_{\text {arom }} \\
(\%)\end{array}$} & \multicolumn{2}{|l|}{ XPS } & \multicolumn{2}{|c|}{ Elemental analysis } \\
\hline & & $\begin{array}{l}\text { Oxygen } \\
(w t \%)\end{array}$ & $\begin{array}{l}\mathrm{C}_{1 \mathrm{~s} 284 \mathrm{eV}} \\
(\%)\end{array}$ & $\begin{array}{l}\mathrm{H} / \mathrm{C} \\
(\mathrm{at} \%)\end{array}$ & $\begin{array}{l}\mathrm{O} \\
(\mathrm{wt} \%)\end{array}$ \\
\hline 1 foam & 62 & 13 & 82 & 44 & 13 \\
\hline 1 granular & 45 & 15 & 87 & 48 & 14 \\
\hline 5 & 30 & 17 & 83 & 52 & 16 \\
\hline
\end{tabular}




\section{Conclusions} foam. acknowledged.

\section{References}

The formation of carbon foam along the pyrolysis of olive stones is facilitated when a reactor containing 200$300 \mathrm{~g}$ of precursor under $1 \mathrm{MPa}$ of inert gas and steam is introduced into a furnace heated at $500^{\circ} \mathrm{C}$. Although the heat transfer from the furnace to the precursor is fast, the exothermicity of the own pyrolysis makes the solid heating occur at a higher rate, a minimum of $30^{\circ} \mathrm{C} / \mathrm{min}$ heating rate being needed to initiate the foam formation, and of $50^{\circ} \mathrm{C} / \mathrm{min}$ for this to occur extensively.

As the micropore volume of the foam is negligible, its low density $\left(0.2-0.3 \mathrm{~g} / \mathrm{cm}^{3}\right)$ is due to the presence of mesopores and macropores, $60-80 \%$ of the pore volume corresponding to pores with a size superior to $1 \mu \mathrm{m}$. In general, a parallelism between degree of foaming and the production of pores of increasing size is observed.

A mechanism is suggested to explain the formation of the foam as a combination of a softening of the precursor and a fragmentation of the biopolymers to produce an intermediate that can be considered as a "melt". A fast increase in temperature reduces the viscosity of the "melt" and facilitates further fragmentation to volatiles, the expansion of which swells the particles to produce the

\section{Acknowledgement}

Financial support of Ministerio de Educación y Ciencia, Spain, project number MAT2004-03480-C02-02 is

[1] Rodríguez-Reinoso F. Production and application of activated carbons. In: Schüth F, Sing KSW, Weitkamp J, editors. Handbook of porous solids, vol. 3. Weinheim: Wiley-VCH; 2002. p. 1766-827.

[2] Ehrburger P, Lahaye J, Wozniak E. Effect of carbonisation on the porosity of beechwood. Carbon 1982;20(5):433-9.

[3] Spradling DM, Guth RA. Carbon foams. Adv Mater Process 2003;161(11):29-31.

[4] Klett JW, McMillan AD, Gallego NC, Burchell TD, Walls CA. Effects of heat treatment conditions on the thermal properties of mesophase pitch-derived graphitic foams. Carbon 2004;42(8-9): $1849-52$.
[5] Klett J, Hardy R, Romine E, Walls C, Burchell T. High-thermalconductivity, mesophase-pitch-derived carbon foams: effect of precursor on structure and properties. Carbon 2000;38(7):953-73.

[6] Inagaki M, Morishita T, Kuno A, Kito T, Hirano M, Suwa T, et al. Carbon foams prepared from polyimide using urethane foam template. Carbon 2004;42(3):497-502.

[7] Marcilla A, Conesa JA, Asensio M, García-García SM. Thermal treatment and foaming of chars obtained from almond shells: kinetic study. Fuel 2000;79(7):829-36.

[8] Kurosaki F, Ishimaru K, Hata T, Bronsveld P, Kobayashi E, Imamura Y. Microstructure of wood charcoal prepared by flash heating. Carbon 2003;41(15):3057-62.

[9] Santamaría-Ramírez R, Romero-Palazón E, Gómez-de-Salazar C, Rodríguez-Reinoso F, Martínez-Saez S, Martínez-Escandell M, et al. Influence of pressure variations on the formation and development of mesophase in a petroleum residue. Carbon 1999;37(3):445-55.

[10] Lide DR. CRC handbook of chemistry and physics. London: CRC Press Inc; 1992. p. 6-172-3.

[11] Minkova V, Razvigorova M, Bjornbom E, Zanzi R, Budinova T, Petrov N. Effect of water vapour and biomass nature on the yield and quality of the pyrolysis products from biomass. Fuel Process Technol 2001;70(1):53-61.

[12] Rodríguez-Valero MA, Martínez-Escandell M, Molina-Sabio M, Rodríguez-Reinoso F. $\mathrm{CO}_{2}$ activation of olive stones carbonized under pressure. Carbon 2001;39(2):320-3.

[13] López-González JD, Martínez-Vilchez F, Rodríguez-Reinoso F. Preparation and characterization of active carbons from olive stones. Carbon 1980;18(6):413-8.

[14] Iley M, Marsh H, Rodríguez-Reinoso F. Adsorptive properties of carbonized olive stones. Carbon 1973;11(6):633-8.

[15] Lede J, Diebold JP, Peacocke GVC, Piskorz J. The nature and properties of intermediate and unvaporized biomass pyrolysis materials. In: Bridgwater A, Czernik S, Diebold J, Meier D, Oasmaa A, Peacocke C, Piskorz J, Radlein D, editors. Fast pyrolysis of biomass: a handbook. Aston University: CPL Press; 1999. p. 51-65.

[16] Antal Jr MJ, Varhegyi G. Cellulose pyrolysis kinetics: the current state of knowledge. Ind Eng Chem Res 1995;34(3):703-17.

[17] Shafizadeh F. Introduction to pyrolysis of biomass. J Anal Appl Pyrol 1982;3(4):283-305.

[18] Reynolds JG, Burnham AK. Pyrolysis decomposition kinetics of cellulose-based materials by constant heating rate micropyrolysis. Energy Fuels 1997;11(1):88-97.

[19] Brunner PH, Roberts PV. The significance of heating rate on char yield and char properties in the pyrolysis of cellulose. Carbon 1980;18(3):217-24.

[20] Bridgwater AV, Czernik S, Piskorz J. The status of biomass fast pyrolysis. In: Bridgwater AV, editor. Fast pyrolysis of biomass: a handbook, 2. Aston University: CPL Press; 2002. p. 1-22.

[21] Mok WSL, Antal Jr MJ. Effects of pressure on biomass pyrolysis. II. Heats of reaction of cellulose pyrolysis. Thermochim Acta 1983; 68(2-3):165-86. 